\title{
Hierarquização das cadeias produtivas: diagnóstico das atividades econômicas de Gramado (RS)
}

\author{
Hierarchy of production chains: diagnosis of economic activities in Gramado (RS)
}

\section{Marcos Paulo Dhein Griebeler}

Faculdades Integradas de Taquara - FACCAT - Taquara - Rio Grande do Sul - Brasil

\section{Franciele Berti}

Faculdades Integradas de Taquara - FACCAT - Taquara - Rio Grande do Sul - Brasil

\section{Alexandre Aloys Matte Junior}

Faculdades Integradas de Taquara - FACCAT - Taquara - Rio Grande do Sul - Brasil

\begin{abstract}
Resumo: Este estudo tem como objetivo analisar as características e as principais atividades econômicas do município de Gramado (RS), destacando de forma sintetizada a relevância de cada uma delas. A partir da identificação e hierarquização das principais cadeias produtivas, apresentam-se atividades com possível capacidade de promover o desenvolvimento econômico de Gramado e região. Além disso, discorre-se acerca de sugestões de ações para fomentar a economia por meio destas. Para tanto, foram utilizados dados fornecidos pela Relação Anual de Informações Sociais (RAIS) de 2015. No que tange as atividades agropecuárias, estas foram identificadas pelo QL agropecuário com base na Produção Agrícola Municipal (PAM) e Pesquisa Pecuária Municipal (PPM). Para fins de análise, utilizou-se a medida de especialização Quociente Locacional (QL), sugerida por Paiva (2006), visando identificar as cadeias mais representativas do município. Além disso, para este estudo de natureza quantitativo e qualitativo, o procedimento metodológico compreendeu, inicialmente, revisão bibliográfica, buscando aprofundar 0 indicador quociente locacional. Realizou-se, também, pesquisa documental em obras que narram a trajetória do município e observação assistemática (MARKONI e LAKATOS, 2017) no recorte espacial. $O$ estudo permitiu confirmar que o turismo é notavelmente o elemento articulador. Além deste, Chocolate, móveis e construção civil já estão associados à atividade turística. Na sequência, Frutas, podem vir a se articular. A fabricação de ferramentas e a cutelaria mostraram-se independentes da atividade turística, no entanto, estas também podem ser combinadas com o turismo para incrementar o desenvolvimento das mesmas.
\end{abstract}

Palavras-chave: Desenvolvimento econômico. Corede Hortênsias. Quociente locacional.

Abstract: This study aims to analyze the characteristics and main economic activities of the city of Gramado (RS), highlighting in a summarized way the relevance of each one of them. From the identification and hierarchization of the main productive chains, activities with possible capacity to promote the economic development of Gramado and region are presented. In addition, there are suggestions for actions to promote the economy through them. For that purpose, data provided by the Annual Social Information Ratio (RAIS) of 2015 were used. Regarding the agricultural activities, these were identified by the agricultural LQ based on Municipal Agricultural Production (PAM) and Municipal Livestock Research (PPM). For purposes of analysis, we used the Locational Quotient (QL) specialization measure, suggested by Paiva (2006), in order to identify the most representative chains of the municipality. In addition, for this quantitative and qualitative study, the methodological procedure initially comprised a bibliographical review, seeking to deepen the locational quotient indicator. Documentary research was also carried out in works that narrate the trajectory of the municipality and unsystematic observation (MARKONI and LAKATOS, 2017 ) in the spatial clipping. The study confirmed that tourism is notably the articulating element. Besides this, Chocolate, furniture and construction are already associated with the tourist activity. In the sequence, Fruits, can come together. The manufacture of tools and the cutlery were independent of the tourist activity, however, these can also be combined with the tourism to increase their development.

Keywords: Economic development. Corede Hortênsias. Locational quotient. 


\section{Introdução}

Verifica-se que as teorias de desenvolvimento regional têm experimentado significativas transformações suscitadas devido ao cenário de mudanças sociais e econômicas. De acordo com Amaral Filho (2001), tais modificações estão relacionadas ao fenômeno da globalização, drásticas transformações nas formas e modos de produção e aberturas da economia nacional. O autor destaca que desde o fim da década de 1980 tem sido observado um movimento endogeneização por parte das regiões do interior dos países, no qual a organização territorial assume as decisões concernentes ao seu destino e ao uso dos recursos utilizados no processo econômico.

Ao se ter este contexto como ponte de partida para a análise, a tese defendida neste estudo está embasada na proposição de Paiva (2006), cujo alicerce está na premissa de que o desenvolvimento endógeno se dá a partir do fortalecimento das competências do território, isto é, buscar crescer de forma sustentável a partir da identificação das suas vantagens, especializando-se nos setores em que se apresenta mais competitivo. A partir da identificação das suas especialidades, pode-se direcionar esforços objetivando reforçar suas particularidades.

O mesmo autor sustenta, ainda, que "toda a especialização regional deve ser pensada em sua dimensão de 'cadeia', tendo em vista que as vantagens competitivas absolutas geradas pela especialização incentivam o processo de "integração regional da cadeia produtiva à qual pertence o 'elo especializado' que deu início ao processo (PAIVA, 2004, p. 21).

Nessa perspectiva, Amaral Filho (2001) enfatiza que, embora não exista uma fórmula padrão, uma estratégia de desenvolvimento embasada nos novos modelos, sugere a implantação ou o fortalecimento de projetos econômicos ligados a algum tipo de "vocação" do território e que se interliguem, envolvendo uma cadeia de atividades.

Entende-se que analisar o território a partir da sua dinâmica produtiva e econômica é essencial a fim de direcionar esforços múltiplos entre o poder público e o privado para o fortalecimento das competências do mesmo.

Desta forma, este estudo tem como objetivo analisar as características e as principais atividades econômicas do município de Gramado, no Rio Grande do Sul, destacando de forma sintetizada a relevância de cada uma delas. A partir da identificação e hierarquização das principais cadeias produtivas, apresentam-se atividades com possível capacidade de promover o desenvolvimento econômico de Gramado e seu entorno. Além disso, discorre-se acerca de sugestões de ações para fomentar a economia regional por meio destas.

Para tanto, foram utilizados dados fornecidos pela Relação Anual de Informações Sociais (RAIS) de 2015. No que tange as atividades agropecuárias, estas foram identificadas com base na Produção Agrícola Municipal (PAM) e Pesquisa Pecuária Municipal (PPM). Para fins de análise, utilizou-se a medida de especialização Quociente Locacional (QL), sugerida por Paiva (2006), visando identificar as cadeias mais representativas do município.

Além disso, para este estudo de natureza quantitativo e qualitativo, o procedimento metodológico compreendeu, inicialmente, revisão bibliográfica, buscando aprofundar 0 indicador quociente locacional, valendo-se de North (1955) e Paiva (2004, 2006, 2014). Realizou-se, também, pesquisa documental em obras que narram a trajetória do município e observação assistemática (MARKONI e LAKATOS, 2017) no recorte espacial.

No que se refere a organização desta análise, inicialmente apresenta-se o Quociente Locacional, bem como parâmetros utilizados neste artigo. Em seguida é exposta a caracterização do município em análise, descrevendo aspectos históricos, demográficos e econômicos do local. Por fim, apresentam-se as principais atividades econômicas no município na contemporaneidade, hierarquizando as cadeias produtivas responsáveis pela dinâmica da economia, bem como sugestões para estimular a economia, seja por meio da especialização ou diversificação produtiva. Por isso, na sequência será 
apresentada, mesmo que brevemente, o Quociente Local, ferramenta utilizada como apoio para a estruturação do presente artigo.

\section{Quociente locacional}

Com o intuito de analisar a estrutura atual do mercado de trabalho no município de Gramado, foram utilizados dados fornecidos pela RAIS do ano de 2015, destacando as principais atividades econômicas pelos seus respectivos Quocientes Locacionais (QLS).

De acordo com North (1955, p. 300), o Quociente Locacional compara a concentração de emprego de um determinado segmento em um área [a economia objeto que, para os nossos propósitos, é a região] com outra área [a economia referência, que para nossos propósitos é a nação].

Paiva (2004) sustenta que o Quociente Locacional é a medida de especialização regional mais utilizada em pesquisas com vistas à identificação da estrutura econômica e das potencialidades dos territórios. Segundo o autor, o QL objetiva confrontar a participação relativa de determinado setor ou segmento produtivo de uma região com a participação relativa desse mesmo setor ou segmento em uma região de referência. Neste sentido, O QL analisa "quantas vezes mais" [ou menos] uma região se dedica a uma determinada atividade em face ao conjunto das regiões que perfazem a macrorregião de referência. Normalmente utiliza-se a participação percentual do emprego num determinado setor como medida de dedicação ou importância a certa atividade (PAIVA, 2006).

Ainda segundo North (1955) é imprescindível estar atento à economia que será utilizada como referência nas comparações. Para o autor, dependendo das características do território objeto de análise, nem sempre optar pela nação como parâmetro de economia é o ideal. Particularmente, no caso do Brasil, caracterizado por profundas diferenças entre as regiões - tendo em vista a dimensão continental que este apresenta - a economia dos estados comumente é mais adequada para estimar se uma determinada atividade está direcionada ao mercado interno ou à exportação.

Isto posto, para este estudo, tomou-se como economia referência o Rio Grande do Sul [estado no qual está inserida Gramado], sendo assim, o QL apresenta a seguinte configuração:

$$
\mathrm{QL}=\frac{\text { (Emprego Ativ. A Gramado) }}{\text { (Emprego Total Gramado) }} \div \text { (Emprego Ativ. A RS) }
$$

Fonte: adaptado de Paiva (2013, p. 77).

No que se refere ao cálculo dos QLS Agropecuários, utilizou-se como fonte de dados brutos: IBGE Produção Agrícola Municipal (PAM) Pesquisa Pecuária Municipal (PPM) Produto Interno Bruto dos Municípios (PIB). Foram coletados dados dos últimos 3 anos publicados no PIB - IBGE (2011, 2012 e 2013) e calculada a média para todas as quantidades produzidas/rebanho da PAM e PPM, tendo em vista que devido às intempéries temporais a produção agropecuária sofre variações, logo fazer a média trianual visa diminuir essa influência das condições meteorológicas. Neste caso, o cálculo dos QLs é baseado na seguinte fórmula: (quantidade da produção no município $X$ / VAB Agropecuário do município) / (quantidade da produção no estado / VAB Agropecuário do estado)

Para este estudo serão considerados significativos os QLs com valores superiores a 1 (um), representando especialização do segmento no munícipio. Além disso, visando identificar a participação mais efetiva do segmento/atividade, foram consultados o número de empregos na atividade.

Após a identificação das cadeias, as atividades foram hierarquizadas, visando identificar as que apresentam considerável capacidade de promover o desenvolvimento econômico de Gramado. Para tanto, embasa-se no sistema de North.

De acordo com Paiva (2014), tal sistema permite distinguir dois tipos de atividades, quais sejam: (i) atividades propulsivas, responsáveis pelo ingresso de renda básica no território e (ii) atividades 
reflexas, que estão direcionadas a atender as demandas locais de consumo. Vale destacar que estas últimas dependem do ingresso monetário inicial, tendo em vista que, embora a circulação interna de bens e serviços também gere renda, não é autossuficiente, assim, deve haver ingresso de recursos monetários do exterior para o interior do território.

O mesmo autor sugere que número de atividades propulsivas de uma região ou localidade é, usualmente, bastante limitado, no entanto, o número de atividades produtivas voltadas à exportação é comumente subestimado. Tal cenário se deve porque os elos das cadeias não são identificados. O autor atenta para a importância deste desmembramento entre atividades propulsivas e reflexas para a formulação de políticas de desenvolvimento regional, tendo em vista que "[...] o tamanho atual e o crescimento futuro do mercado interno de qualquer economia regional é determinado pelo tamanho atual e crescimento futuro de suas atividades propulsivas" (PAIVA, 2014, p. 38).

Dentre as atividades propulsivas, existem que são consideradas essenciais:

(i) $\mathrm{X}$ propulsivas ${ }^{1}$ - direcionadas ao mercado externo, via exportação de bens;

(ii) Trs propulsivas ${ }^{2}$ - direcionadas ao atendimento de demandas de agentes que recebem rendimento fora do território;

(iii) $\mathrm{G}$ propulsivas ${ }^{3}$ - atividades financiadas pelo governo.

No que se refere as atividades reflexas, estas são classificas: Consumo reflexo, direcionadas ao atendimento das demandas da população local (famílias) e Genérico reflexas, direcionadas ao atendimento das demandas da população local (famílias - SPF) e demandas dos diversos empreendimentos locais (empresas SPE).

\footnotetext{
1 A sigla "X propulsiva" deriva da notação convencional para Exportação (X) (PAIVA, 2013, p. 49).

2 O símbolo "TrS" busca resgatar o fato desta renda advir de Transferências privadas associadas a aquisição de Serviços no Território por Turistas (vale dizer, por não domiciliados) (PAIVA, 2013, p. 102).

3 A sigla "G propulsiva" deriva da notação convencional para Gasto Governamental (G) (PAIVA, 2013, p. 49).
}

Ao se ter como recorte espacial desta pesquisa o município de Gramado (RS), na próxima seção serão apresentadas as características, bem como aspectos históricos, demográficos e econômicos.

\section{Gramado e seus aspectos históricos, demográficos e econômicos}

Gramado localiza-se no estado do Rio Grande do Sul, a 885 metros de altitude, na encosta inferior do nordeste. É constituído por uma população de 32.273 habitantes (IBGE, 2010), distribuída em uma área de 237,827 km² (IBGE, 2016). O município é reconhecido pelo Ministério do Turismo (2008) como um dos 65 destinos indutores do desenvolvimento turístico do Brasil.

A história do município de Gramado remonta ao século XIX, quando, em 1875, houve início a colonização por descentes de portugueses, posteriormente, imigrantes de alemães e italianos também se estabeleceram no município. Em 19 de abril de 1904, por meio do ato Municipal $\mathrm{n} \cong$ ㄴ 72, Gramado passa à condição de 5ํDistrito de Taquara, com sede na Linha Nova, nove anos depois a sede distrital é transferida para o atual centro urbano. Em 1938, o povoado de Gramado é elevado à Vila e em 15 de dezembro de 1954 por meio a Lei Estadual no 2.522, Gramado torna-se um município (CASAGRANDE, 2006).

Segundo Dorneles (2001), desde o primeiro censo realizado em 1955, Gramado apresenta crescimento da população. De acordo com o Censo Demográfico do Instituto Brasileiro de Geografia e Estatística (IBGE) realizado no ano de 1991, o município registrava 22.095 habitantes, em 2000 a população era de 28.593 e, atualmente, compõe-se de 32.273 habitantes (IBGE, 2010).

No que se refere ao aumento populacional do município estudado, Lopes (2014) menciona que o fato está diretamente relacionado às oportunidades de emprego que a atividade turística gera. Neste sentido, Dorneles (2001) atenta para o fato de outros municípios pertencentes ao mesmo Conselho 
Regional de Desenvolvimento (Corede) ${ }^{4}$ apresentarem queda nos percentuais populacionais, como é o caso São Francisco de Paula e Cambará do Sul.

Pelo critério do governo do Estado, Gramado pertence ao Corede Hortênsias, criado em 1991, e é composto por mais seis municípios: Cambará do Sul, Canela, Jaquirana, Nova Petrópolis, Picada Café e São Francisco de Paula (Figura 1).

\section{Figura 1 - Localização Corede Hortênsias}

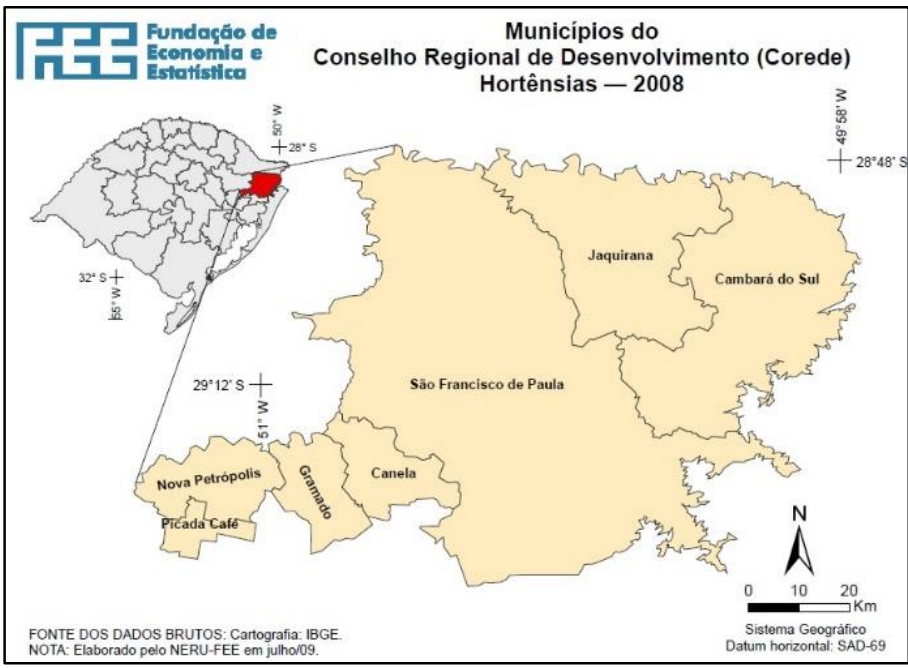

Fonte: FEE (2008).

O Corede Hortênsias apresenta uma estrutura agrícola diversificada, destacando-se produtos da lavoura temporária, como batata inglesa, alho e tomate. Nos maiores municípios, nos campos de altitude, a silvicultura e a produção de bovinos de corte e de leite lideram. Naqueles menores, a criação de aves é a que desponta (BERTÊ et al., 2016). A Indústria de transformação é acentuada no que se refere a empregabilidade, já os segmentos tradicionais como a produção de calçados, móveis, produtos de metal e laticínios destacam-se por possuir um perfil industrial especializado em setores não dinâmicos.

No que se refere aos aspectos econômicos de Gramado, ainda que ao longo da trajetória do município tenham sido registradas oscilações na demanda turística, historicamente o município evidencia vocação turística. De acordo com Lopes

\footnotetext{
${ }^{4}$ Fórum de discussão e decisão a respeito de políticas e ações que visem ao desenvolvimento regional (CONSELHO REGIONAL DE DESENVOLVIMENTO, 2017).
}

(2014), após a formação urbana, a economia gramadense sempre esteve atrelada à atividade turística. Segundo a autora, o turismo foi fomentado na década de 1920 com a chegada da linha férrea em Gramado; frente à facilitação do acesso, a cidade consolidou-se como destino turístico, tornando-se reconhecida e recomendada pelos médicos para o turismo de saúde ${ }^{5}$. Entre as décadas de 1920 e 1950 o número de visitantes em busca do local reconhecidamente revigorante, de descanso e cenário de saúde cresceu continuamente, no entanto, o município explorava paralelamente o turismo de lazer (GOVERNO DO ESTADO DO RIO GRANDE DO SUL, 2016).

Não obstante, na década de 1950 o setor turístico em Gramado sofreu uma redução. Segundo Vidal et al. (2014) respaldados em dados da memorialista Marilia Daros, esta queda no fluxo turístico esteve, fundamentalmente, relacionada a dois fatores: o primeiro foi o surgimento do veraneio no litoral norte gaúcho e, o segundo, a transição da matriz de transporte ferroviário para transporte rodoviário, processo este iniciado pelo Governo Federal.

Neste contexto, de acordo os mesmo autores, a economia local direcionou-se à industrialização, emergindo em Gramado uma cadeia coureirocalçadista. A cadeia se fortaleceu e em 1995 o município sediava a empresa que liderava o mercado nacional. A economia do munícipio se expandiu e especializou-se no setor, atraindo diversas atividades econômicas atreladas ao ramo do calçado.

No ano de 1985 a atividade industrial representava $77,38 \%$ do produto interno bruto que o município produziu, seguido das atividades comerciais que representavam 17, 87\% (GRAMADO, 1987).

De acordo com Vidal et al. (2014), em 1990 a indústria era responsável por $57,35 \%$ do valor

\footnotetext{
5 Atualmente o turismo de saúde possui duas ramificações: turismo de bem-estar e turismo médico-hospitalar (MINISTÉRIO DO TURISMO, 2010). No entanto, a atividade turística explorada em Gramado no período referenciado remete ao turismo de bem-estar, que objetiva, essencialmente, a diminuição dos níveis de estresse e a prevenção e/ou amenização de determinadas doenças, tal como a tuberculose, por exemplo.
} 
agregado bruto e o setor de serviços por 39\%. Em 1994 a globalização fomentou a competitividade, o segmento calçadista foi violentamente afetado devido à implantação do plano real e abertura de exportações. Tais fatores culminaram na "falência generalizada" em todas as atividades ligadas ao setor. Neste cenário, Gramado encontrou o turismo como alternativa para absorção da mão-de-obra.

No entanto, observa-se que a escolha de direcionar a economia para o turismo não ocorreu aleatoriamente, uma vez que, concomitante a industrialização, a atividade turística permanecia movimentando o munícipio. Apesar do declínio nas atividades turísticas em determinados períodos [conforme mencionado anteriormente], Gramado continuou investindo no setor (GOVERNO DO ESTADO DO RIO GRANDE DO SUL, 2016).

A década de 1960 esteve marcada pela expansão da cidade e a presença do turismo, período em que também iniciavam-se os loteamentos no município, atraindo a atenção de investidores imobiliários (LOPES, 2014). Deste modo, Gramado se preparava para receber turistas, nesta fase houve crescimento no número de empreendimentos para fins de segunda residência, tendência esta já percebida no final da década de 1930:

Pela Lei Estadual no 7.199 de 31 de março de 1938, o povoado de Gramado foi elevado à Vila, apresentando já nesta época, algumas casas de veraneio e, as primeiras divisões de terras eram realizadas junto ao centro da cidade (GRAMADO, 1987, p. 25).

Neste contexto, o potencial turístico da localidade passou a ser cada vez mais explorado. Atualmente, Gramado consiste em um núcleo turístico referência no segmento em âmbito nacional e imagem de destino consolidado. Munido de infraestrutura modelo no país, o município recebe anualmente seis milhões de visitantes tendo sua economia intensamente firmada no turismo de lazer e eventos (MINISTÉRIO DO TURISMO, 2015).

$\mathrm{Na}$ sequência, analisa-se a estrutura atual do mercado de trabalho de Gramado, apresentando a hierarquização das cadeias produtivas, bem como a respectiva função dinâmica.
4 Hierarquização das cadeias produtivas: diagnóstico das principais atividades econômicas de Gramado

A partir dos QLs e setores identificados foram agrupadas as cadeias produtivas segundo a sua função dinâmica. Considerando-se um total de 17.689 trabalhadores urbanos e um total de 2.292 estabelecimentos no município de Gramado, identificou-se que a cadeia de turismo e lazer é responsável direta por aproximadamente 6.884 empregos formais, evidenciando a especialização produtiva de Gramado na cadeia.

O Quadro a seguir apresenta a agregação das principais cadeias produtivas de Gramado, com base nos resultados da RAIS de 2015.

\section{Quadro 1 - Agregação das principais cadeias produtivas de Gramado (RS) com base nos resultados da RAIS 2015}

\begin{tabular}{|c|c|c|}
\hline Cadeia principal & $\begin{array}{l}\text { Função } \\
\text { dinâmica }\end{array}$ & $\begin{array}{c}\text { Número de } \\
\text { trabalhadores }\end{array}$ \\
\hline Turismo e Lazer & Trs propulsiva & 6.884 \\
\hline $\begin{array}{l}\text { Serviço prestado às } \\
\text { famílias }\end{array}$ & $\begin{array}{l}\text { Consumo } \\
\text { reflexo }\end{array}$ & 798 \\
\hline $\begin{array}{c}\text { Serv. prestado às } \\
\text { famílias e empresas }\end{array}$ & Genérico reflexo & 746 \\
\hline Indeterminada & Indeterminada & 545 \\
\hline Construção civil & X propulsiva & 906 \\
\hline $\begin{array}{c}\text { Madeira, mobiliário } \\
\text { e papel }\end{array}$ & X propulsiva & 2.084 \\
\hline $\begin{array}{c}\text { Serviços de } \\
\text { organizações } \\
\text { sociais }\end{array}$ & multifunção & 128 \\
\hline Multicadeia & X propulsiva & 400 \\
\hline $\begin{array}{l}\text { Utensílios } \\
\text { Domésticos }\end{array}$ & $\mathrm{X}$ propulsiva & 123 \\
\hline $\begin{array}{l}\text { Serviços públicos } \\
\text { básicos-Educação }\end{array}$ & $\begin{array}{l}\text { Consumo } \\
\text { reflexo }\end{array}$ & 90 \\
\hline Multicadeia & Multifunção & 150 \\
\hline $\begin{array}{l}\text { Serviços prestados } \\
\text { às empresas }\end{array}$ & $\begin{array}{l}\text { Genérico } \\
\text { Reflexo }\end{array}$ & 17 \\
\hline
\end{tabular}

Fonte: Elaborado pelos autores (2017). 
$\mathrm{Na}$ referida cadeia, a atividade denominada Parques de diversão e parques temáticos é a que apresenta o maior QL $(46,65)$, empregando 275 pessoas. Embora o QL da atividade seja elevado [0 que significaria especialização no segmento], percebe-se que o número de empregos gerados é considerável, mas não substancial. Esse cenário também é percebido nas atividades relacionadas a jardins botânicos com QL 17,80 e empregando, apenas, 26 pessoas. Este quadro, de QL elevado, porém com limitada geração de emprego, se dá, possivelmente, devido à baixa dedicação à atividade no Rio Grande do Sul [economia referência para este estudo], conforme Paiva $(2013,87)$ " [...] é importante estar atento para o impacto sobre o indicador da economia que nos serve de referência para comparações.

Diferentemente do que ocorre no caso acima citado, a atividade de hotéis e similares, também pertencente à cadeia de turismo e lazer, apresenta QL elevado $(24,04)$ mas emprega 2.615 pessoas, sendo a atividade que mais gera emprego formal no município:

A vocação turística e hoteleira de Gramado desabrochou no final da segunda década do século XIX. Em 1919 o munícipio já possuía uma hospedaria que recepcionava "viajores". No ano de 1987 Gramado registrava, dentre hotéis e pousadas, vinte e nove estabelecimentos de hospedagem. Atualmente, a atividade de hotéis e similares contabiliza 155 estabelecimentos (FEE, 2015), dispondo de mais de 11 mil leitos.

A segunda atividade de lazer e turismo que mais gera emprego formal é a denominada "Restaurantes e outros estabelecimentos de serviços de alimentação e bebidas", originando 1.617 empregos, em seguida, desponta a atividade de fabricação de produtos derivados do cacau, de chocolates e confeitos.

A relação entre Gramado e a fabricação de chocolates é estreita e antiga. A história do chocolate em Gramado tem origem em 1976 quando, após uma viagem para Bariloche e observando a similaridade entre cidade argentina e Gramado, Jayme Prawer implantou no município a primeira fábrica de chocolate caseiro, algo até então inédito no Brasil. De acordo com Vargas e Gastal (2015) paralelo a outras atividades, o chocolate foi relevante para o desenvolvimento do município, atingindo, contemporaneamente, dimensões que o tornaram um "ícone gramadense".

Algumas atividades da cadeia Turismo e Lazer também foram identificadas como "Serviços prestados às famílias", ou seja, a especialização se dá devido à prestação de serviços para turistas, no entanto, as famílias domiciliadas também usufruem dos serviços [frequentando, por exemplo, bares, restaurantes, lojas de chocolates, lojas de vestuário, entre outros].

A atividade de fabricação de móveis com predominância em madeira é segunda que mais gera emprego formal no município, empregando 2.084 pessoas. A tradição moveleira local remonta década de 1940, no entanto, é Elizabeth Rosenfeldt que torna Gramado referência no segmento moveleiro. Diante do empreendedorismo de Rosenfeldt, que fundou o Artesanato Gramadense, outras fábricas de móveis se instalaram no município (VARGAS e GASTAL, 2015). No final da década de 1980 Gramado registrava 31 fábricas de móveis em madeira (GRAMADO, 1997). Atualmente identifica-se 85 estabelecimentos de fabricação de móveis, sendo 84 com predominância em madeira (FEE, 2015). No entanto, vale ressaltar que historicamente, em Gramado, a fabricação de móveis em madeira está, em parte, relacionada ao turismo

Entretanto, a atividade de fabricação de móveis também está articulada com a atividade turística, logo, infere-se que uma fração considerável da atividade seja estimulada por efeito da cadeia de turismo e lazer. Vale mencionar que historicamente as primeiras confecções dos móveis já eram destinadas consideravelmente para turistas, conforme destaca Rubim (1999).

Outra cadeia geradora de empregos é a da construção civil, empregando em torno de 900 pessoas. Extrapolando a atividade de construção de edifícios, neste grupo é possível identificar produtos e 
serviços característicos da função, tais como serviços de arquitetura, obras de terraplanagem, obras de acabamento, entre outros. No entanto, infere-se que a cadeia seja movimentada fundamentalmente pela atividade turística, tendo em vista a intensa construção de equipamentos turísticos que se observa no local, especialmente os de hospedagem. Neste contexto, a cadeia de turismo e lazer assume uma posição ainda mais significativa na economia de Gramado.

A fabricação de ferramentas apresentou QL relevante que, juntamente com a atividade de Comércio Atacadista de ferragens e ferramentas, emprega aproximadamente 390 pessoas, distribuídas em 9 estabelecimentos do ramo. Desde de 1953 está sediada em Gramado uma imponente indústria de ferramentas manuais. Já no ano de 1985, a metalúrgica era o terceiro setor em importância para a economia do município (GRAMADO, 1987)

Após a identificação das cadeias, as atividades devem ser hierarquizadas, visando identificar as que apresentam maior capacidade de promover 0 desenvolvimento econômico do território. Tal sistema permite distinguir dois tipos de atividades, quais sejam: (i) atividades propulsivas, responsáveis pelo ingresso de renda básica no território, são voltadas para exportação e (ii) atividades reflexas, que estão direcionadas a atender as demandas locais de consumo (PAIVA, 2014)

Importa mencionar que as atividades reflexas [voltadas ao atendimento das demandas locais de consumo] são movimentadas devido à existência de um mercado interno de consumo, no entanto, elas pressupõem que os moradores tenham auferido algum poder de compra, alguma renda, e , conforme sublinha Paiva (2014), é preciso atentar-se para a origem desta renda, ou seja, identificar por quais atividades há ingresso de recursos monetários do exterior para o interior do território, ou seja, mapear quais são as atividades propulsivas.

Diante da análise do Quadro 1, identifica-se que o município se caracteriza como um polo turístico. Com base em Paiva (2014), se o território apresentar QLs elevados no setor de serviço é uma condição clara de que este é um polo, uma vez que os polos são responsáveis pelo fornecimento de serviços "relativamente sofisticados", seja de saúde, educação, comercial, consultoria e de cultura, lazer e turismo para uma população maior do que a dos domiciliados.

Como é possível observar no decorrer deste estudo, as atividades reflexas são desdobramentos [ou reflexo] das atividades propulsivas. Deste modo, recomenda-se intensificar as atividades propulsivas para estimular as atividades reflexas [que se retroalimentarão]. Logo, no caso de Gramado, inferese que, visando promover o desenvolvimento, é primordial fomentar a atividade turística

Conforme Vargas (1998), o turismo é uma das atividades preferidas por novas formas de gestão urbana, considerando-o forte impulsionador do desenvolvimento local. A representatividade do setor turístico é inquestionável, de acordo com a Organização Mundial do Turismo (OMT, 2014), em 1950 o número de viajantes internacionais era de 278 milhões, em 2013 apurou-se 1,1 bilhão de turistas internacionais. Observa-se, portanto, a potência do turismo, tendo em vista seu crescimento de forma continua nas últimas décadas.

Pesquisa realizada pelo Gramado, Canela e Região das Hortênsias Convention \& Visitors Bureau $(G C R H C \& V B)^{6}$ evidencia que 0 tempo de permanência do turista de Eventos e Negócios em Gramado é, em média, de três dias. Sendo assim, sugere-se aumento no leque de atratividades oferecidos, especialmente cultural e natural, visando estimular maior permanência dessa tipologia de turista no destino. Conforme alude Paiva (2014, p.57), "Quanto mais diversificados forem os atrativos de um território, maiores as chances do mesmo receber visitantes e destes despenderem um tempo maior no território".

O aumento no tempo de permanência do turista no município geraria mais tempo de ocupação

\footnotetext{
${ }^{6}$ Fundação Civil sem fins lucrativos que objetiva fomentar o turismo na Região das Hortênsias como destino, através de ações de apoio a captação de eventos de natureza técnicocientificas (nacionais e internacionais), além de atrair visitantes através de ações planejadas e integradas de marketing (GRAMADO, CANELA E REGIÃO DAS HORTÊNSIAS CONVENTION \& VISITORS BUREAU, 2016).
} 
na rede hoteleira, aumentaria o consumo em bares e restaurantes, comércio de vestuário e chocolates, por exemplo, contribuindo, portanto, para a multiplicação das demais atividades.

Vale destacar, ainda, a sazonalidade, tradicionalmente inerente ao mercado turístico. A temporalidade age diretamente no rendimento dos empreendimentos turísticos, logo, essa instabilidade suscita ocupações temporárias de alta rotatividade, fator que, por conseguinte, contribui para a elevação de empregos informais (SOARES, 2005).

Neste sentido, o turismo de eventos é considerado uma alternativa para diminuir a sazonalidade e, por consequência, os reflexos adversos concernentes a ela, conforme destacam alguns autores, tais como Crosdales e Tomazzoni (2010), Neri (2003), Hoeller (1999) e Ministério do Turismo (2010), tendo em vista que a realização do evento não está condicionado a atrativos culturais e naturais exuberantes.

Nesta perspectiva, o poder público pode traçar estratégias e medidas para atenuar a sazonalidade do destino. Por meio de alianças entre o poder público, privado e outros órgãos de turismo é possível convergir para a minimização das oscilações turísticas, dinamizando a economia do município e região regularmente.

Vale lembrar que o participante da referida tipologia de turismo apresenta característica comuns, tais como: escolaridade superior; poder aquisitivo elevado; exigência de praticidade e comodidades, atendimento e equipamentos de qualidade; realização de gastos elevados em relação a outros segmentos (MINISTÉRIO DO TURISMO, 2010).

Ainda que o turismo esteja sendo cada vez mais explorado no município, destacamos outra modalidade de turismo, ainda pouco explorada no munícipio: o turismo rural. Embora seja um fenômeno ainda incipiente no meio rural brasileiro, tem se fortalecido enquanto alternativa para obtenção de maiores rendimentos, bem como para a manutenção do homem no campo (TULIK, 2010). A modalidade seria, também, uma maneira de propagar a história do município, bem como valorizar as culturas e complementar a renda das famílias residentes.

Conforme observa Breitbach (2005) a maioria da literatura referente ao desenvolvimento regional enaltece a especialização como o direcionamento ideal para a inserção nos mercados, assim, as regiões deveriam buscar vantagens destacando suas singularidades, aperfeiçoando as suas particularidades. No entanto, segundo a autora, uma "estrutura diversificada e baseada em recursos endógenos" também é uma alternativa eficaz para enfrentar os desafios do desenvolvimento regional, destacando-se, por exemplo, para a dinamização da economia local em caso de condições desfavoráveis "permitindo que os ramos com melhor desempenho assumam o comando, quando alguns passam por dificuldades" (BREITBACH, 2005, p.4).

Neste sentido, aponta-se para a segunda cadeia que mais gera emprego formal no munícipio: Madeira-mobiliário e papel, neste caso direcionado para a fabricação de móveis com predominância em madeira. Frente às mudanças economias, entende-se que a cadeia poderia absorver possível mão-de-obra dispensada da atividade turística, adaptando-se às condições de mercado. No que se refere a especialização agropecuária, destaca-se aquela em fruticultura, conforme tabela a seguir.

\section{Tabela 1 - 15 maiores QLs base PAM e PPM de} Gramado (RS)

\begin{tabular}{cc}
\hline VBP & QL \\
\hline & \\
Figo & 38,536 \\
Caqui & 19,510 \\
Mel de abelha & 8,920 \\
Goiaba & 7,999 \\
Cebola & 7,055 \\
Caprino & 5,270 \\
Batata-doce & 4,448 \\
Laranja & 4,133 \\
Tomate & 2,619 \\
Mandioca & 2,479 \\
Uva & 1,977 \\
Pêssego & 1,839 \\
Tangerina & 1,815 \\
Batata-inglesa & 1,273 \\
Milho (em grão) & 1,212
\end{tabular}

Fonte: Paiva (2016) 
Quando observada a Tabela 1, que é composta pelos 15 maiores QLs identificados na agropecuária gramadense, nota-se que 7 estão representados por frutas, tais como Figo (QL 38,53) e Caqui (QL 19,51), significando alto grau de especialização. Percebe-se, também, que não há especialização na pecuária.

Neste sentido, entende-se que, dentre outras maneiras, a agricultura poderia ser fomentada com o já citado turismo rural. As frutas, por exemplo, poderiam ser utilizadas para fabricação de compotas e outros produtos coloniais que poderiam ser ofertados aos turistas.

De uma maneira global, o estudo permitiu confirmar que o município se configura como um polo turístico, apresentando mais de 6 mil empregos voltados diretamente para a atividade. Neste sentido, sugerimos o fomento do turismo por meio do aumento dos atrativos turísticos, visando maior tempo de permanência do visitante na cidade, especialmente no que se refere ao turista de Negócios e Eventos, tendo em vista essa tipologia de turista despende gastos mais elevados em relação a outros segmentos. Dentre os atrativos, mencionamos 0 turismo rural, tipologia turística ainda pouco explorada no município.

Entretanto, se a estratégia para o desenvolvimento econômico do município for a diversificação produtiva, sugere-se a cadeia madeira mobiliário e papel, representada aqui pela fabricação de móveis, que apresenta alto grau de especialização e gera um número considerável de empregos. Da mesma forma, pode-se citar a fabricação de ferramentas.

\section{Considerações finais}

Este estudo tem como objetivo analisar as características e as principais atividades econômicas do município de Gramado (RS), destacando de forma sintetizada a relevância de cada uma delas. A partir da identificação e hierarquização das principais cadeias produtivas, apresentam-se atividades com possível capacidade de promover o desenvolvimento econômico de Gramado e seu entorno. Além disso, discorre-se acerca de sugestões de ações para fomentar a economia por meio destas. Para tanto, foram utilizados dados fornecidos pela Relação Anual de Informações Sociais (RAIS) de 2015.

No que tange as atividades agropecuárias, estas foram identificadas pelo QL agropecuário com base na Produção Agrícola Municipal (PAM) e Pesquisa Pecuária Municipal (PPM). Para fins de análise, utilizou-se a medida de especialização Quociente Locacional (QLs), sugerida por Paiva (2006), visando identificar as cadeias mais representativas do município.

É notório que um compilado de ações efetivas e empreendedoras, juntamente com uma comunidade hospitaleira e visionária proporcionou o desenvolvimento da atividade turística em Gramado, incialmente com serviços de hospedagem e alimentação, aproveitando-se das belezas naturais e utilizando-as como atrativo para aumentar gradualmente o número de visitantes.

O estudo permitiu confirmar que o município se configura como um polo turístico, apresentando quase sete mil empregos formais voltados diretamente para a atividade. Neste sentido, sugerese o fomento do turismo por meio do aumento dos atrativos turísticos, visando estender o tempo de permanência do visitante na cidade, especialmente no que se refere ao turista de Negócios e Eventos, tendo em vista essa tipologia de turista despende gastos mais elevados em relação a outros segmentos. Dentre os atrativos, mencionamos o turismo rural, tipologia turística ainda pouco explorada no município.

Entretanto, se a estratégia para 0 desenvolvimento econômico do município for a diversificação, sugere-se a cadeia madeira mobiliário e papel, representada aqui pela fabricação de móveis, que apresenta alto grau de especialização e gera um número considerável de empregos. Da mesma forma, pode-se citar a fabricação de ferramentas.

No que tange a agropecuária, identificou-se especialização em fruticultura. Deste modo, entendese que, dentre outras maneiras, a agricultura poderia 
ser fomentada com o já citado turismo rural. As frutas, por exemplo, poderiam ser utilizadas para fabricação de compotas e outros produtos coloniais que poderiam ser ofertados aos turistas.

De qualquer forma, a pesquisa permite concluir que o turismo é notavelmente 0 articulador. Chocolate, móveis e construção civil já estão associados à atividade turística. Frutas, conforme mencionado, podem vir a se articular. A fabricação de ferramentas e a cutelaria mostraram-se independentes da atividade turística, no entanto, estas também podem ser combinadas com o turismo para incrementar o desenvolvimento das mesmas.

Os demais municípios do Corede Hortênsias podem fruir-se do desempenho turístico gramadense, valendo-se de atrativos naturais [especialmente Cambará do Sul, Jaquirana e São Francisco de Paula, que são municípios com acanhada infraestrutura turística mas atraentes no que se refere a natureza] para incitar a visitação introdutória e, posteriormente, desenvolver estrutura adequada. Tal panorama poderia ser atingido por meio de parcerias entre os municípios, formando alianças entre o poder público e o privado, objetivando direcionar esforços conjuntos com vista ao desenvolvimento da região. Por último, para pesquisas futuras, sugere-se avaliar com mais profundidade os fatores que impedem o turista de permanecer mais dias em Gramado e, consequentemente, na região.

\section{Referências}

AMARAL FILHO, J. do. A endogeneização no desenvolvimento econômico regional e local. Planejamento e políticas públicas, n. 23, 2009.

BERTÊ, A. M. de A. et al. Perfil socioeconômico Corede Hortênsias. Boletim Geográfico do Rio Grande do Sul, Porto Algre, v. 26, p.336-371, fev. $16 . \quad$ Disponível em: $<$ file:///C:/Users/Usuario/Downloads/374222269-1-SM.pdf>. Acesso em: 04 ago. 2017
BRASIL. Ministério do Turismo. Gramado (RS) aposta na expansão do turismo de negócios. 2015. Disponível em: http://www.turismo.gov.br/\%C3\%BAltimasnot\%C3\%ADcias/5109-gramado-(rs)-apostana-expansao-do-turismo-denegocios.html>.Acesso em: 12 set. 2016.

BREITBACH, Á. C.M. Entre especialização e diversificação industrial: por um desenvolvimento regional durável. Perspectiva Econômica, v. 1, n. 2, p. 1-30, 2005.

BRASIL. Ministério do Turismo. Turismo de negócios e eventos: Orientações básicas. Brasília: Mtur, 2010. 66 p. Disponível em: <http://www.turismo.gov.br/sites/default/turismo /o_ministerio/publicacoes/downloads_publicaco es/Turismo_de_Negocios_e_Eventos_Orientac oes_Basicas.pdf>. Acesso em: 20 set. 2016.

BRASIL. Brasil. Ministério do Turismo. Estudo de competitividade dos 65 destinos indutores do desenvolvimento turístico regional. Brasília: Brasil, 2008. 84 p. Disponível em: <http://www.turismo.gov.br/sites/default/turismo /o_ministerio/publicacoes/downloads_publicaco es/MIOLO_65xdestinosx_revisao4set.pdf>. Acesso em: 04 ago. 2017.

CASAGRANDE, G. R.. Um cheiro do vinho: presença italiana em Gramado. 2006. Dissertação de Mestrado. Pontifícia Universidade Católica do Rio Grande do Sul.

CONSELHO REGIONAL DE DESENVOLVIMENTO. O que são e como funcionam os Coredes? Disponível em: <http://www.coredesul.org.br/Pagina/9/O-QUESAO-E-COMO-FUNCIONAM-OS-COREDESRS>. Acesso em: 05 maio 2017.

CROSDALES, L. del C. C.; TOMAZZONI, E. L.. Organização e gestão do evento natal luz e 
seus retornos para o turismo de Gramado (RS). UCS, Caxias, v. 1, n. 1, p.1-16, 04 ago. 2017.

DORNELES, E. B.. Gramado: a produção e consumo de uma imagem de cidade europeia no sul do Brasil. Dissertação de mestrado. Universidade Federal do Rio grande do Sul. Porto Alegre, 2001.

FEE (Fundação de Economia e Estatística). Mapas. Disponível em: <http://mapas.fee.tche.br/wpcontent/uploads/2009/08/corede_hortensias_2 008_municipios.png>. Acesso em: 05 maio 2017.

IBGE (INSTITUTO BRASILEIRO DE GEOGRAFIA E ESTATÍSTICA). Censo Demográfico 2010. Disponível em: <http://cod.ibge.gov.br/NRF>. Acesso em: 12 set. 2016.

IBGE (INSTITUTO BRASILEIRO DE GEOGRAFIA E ESTATÍSTICA). Área da unidade territorial $2016 . \quad$ Disponível em: https://cidades.ibge.gov.br/v4/brasil/rs/gramado /panorama. Acesso em: 20 jul. 2017.

\section{GRAMADO CANELA E REGIÃO DAS HORTÊNSIAS} CONVENTION E VISITORS BUREAU (Gramado). Estudo do Perfil do Turista de Eventos. Gramado: Gramado, Canela e Região das Hortênsias Convention e Visitors Bureau, 2016. 13 p.

GRAMADO. Secretaria Municipal de Educação. Gramado, simplesmente Gramado. Gramado, 1987.

GOVERNO DO ESTADO DO RIO GRANDE DO SUL. Atividades características do turismo no RS, em 2013: Valor Adicionado Bruto no Estado, regiões do turismo e municípios. Porto Alegre, 2016. 41 p. Disponível em: <
https://goo.gl/JC6FzL >. Acesso em: 04 ago. 2017.

HOELLER, E. H. Turismo de eventos: Centreventos Cau Hansen de Joinville-SC. Turismo: segmentação de mercado. São Paulo: Futura, 1999.

KUNZ, J. G. et al. A Clusterização do Turismo em Gramado-RS: Breves Notas. Revista Rosa dos Ventos, v. 4, p. 609-614, 2012.

LIMA, E. N. de. O turismo rural como alternativa de desenvolvimento e diversificação de renda no roteiro raízes coloniais em Gramado - RS e as motivações para a adoção da atividade turística nas propriedades do roteiro. 2013. 43 f. TCC (Graduação) - Curso de Desenvolvimento Rural, Faculdade de Ciências Econômicas da Ufrgs, Picada Café, 2013. Disponível em: <http://hdl.handle.net/10183/87469>. Acesso em: 12 set. 2016 .

LOPES, D. C. Assentamentos informais em cidades turísticas: uma análise de Canela e Gramado (RS). 2014.

MARCONI, M. A., LAKATOS, E. M. Fundamentos de Metodologia Científica, 8a edição. Atlas, 01/2017. [Minha Biblioteca].

NÉRI, L. de F. Eventos no Litoral do Paraná e o Problema da Sazonalidade. In: BAHL, M. (Org.). Eventos: A Importância para o Turismo do Terceiro Milênio. São Paulo: Editora Roca, 2003.

NORTH, D. Location Theory and Regional Economic Growth. Journal of Political Economy, LXIII, 1955. Versão em português: MARTINS, M. D. C. S Economia Regional: textos escolhidos. Belo Ho 
Organização Mundial do Turismo. Panorama OMT del turismo internacional. [s. L.], 2014. 16 p. Disponível em: <http://www.eunwto.org/doi/pdf/10.18111/9789284416202>. Acesso em: 04 ago. 2017

PAIVA, C. A. Como identificar e mobilizar o potencial de uma região para o desenvolvimento endógeno. Porto Alegre: Fundação de Economia e Estatística (documento FEE no 59). 2004. Disponível em: $<$ www.fee.tche.br/sitefee/download/documento s/documentos_fee_59.pdf>. Acesso em: 10 dez 2016.

PAIVA, C. A. Dados e mapas. 2016. Disponível em: $<$ http://territoriopaiva.com.br/dados-emapas/dados-municipais>. Acesso em: 05 maio 2017.

PAIVA, C. Á. Desenvolvimento regional, especialização e suas medidas. Indicadores Econômicos Fee, Porto Algre, v. 34, n. 1, p.89102, jul. 2006. Disponível em: <http://revistas.fee.tche.br/index.php/indicadore s/article/view/1446/1810>. Acesso em: 04 ago. 2017.

PAIVA, C. A. Fundamentos da Análise e do Planejamento de Economias Regionais. Foz do Iguaçu: Editora Parque Itaipu, 2013.

PAIVA, C. A. Indicadores Socioeconomicos. 2016. Disponível em: <http://territoriopaiva.com.br/dados-emapas/dados-municipais/indicadoreseconomicos>. Acesso em: 20 dez. 2016.

PAIVA, C. A. Plano de Desenvolvimento Econômico de Foz do Iguaçu. 2014. Disponível em:<http://www.hlucas.com.br/blog/wpcontent/uploads/2014/04/PDE-FOZCOMPLETO-2014.04.24.pdf>. Acesso em: 10 dez 2016.
RUBIM, R. Artesanato Gramadense: um breve relato. Raízes de Gramado III. Gramado: Prefeitura Municipal de Gramado, 1999.

SOARES, L. A. S. Turismo e trabalho informal: um binômio inevitável? Revista Ibero Americana de Estratégia, v. 4, n. 1, 2005.

TULIK, O. Turismo e desenvolvimento no espaço rural: abordagens conceituais e tipologia. In: SANTOS, Eurico de Oliveira; SOUZA, Marcelino de. . Barueri: Manole Ltda, 2010. p. $2-22$.

VARGAS, D. P. de; GASTAL, S. CHOCOLATE E TURISMO: O PERCURSO HISTÓRICO EM GRAMADO, RS. Turismo-Visão e Ação, v. 17, n. 1, p. 66-102, 2015.

VIDAL, R; BURKHARD, D.; MORAIS, R. T. R. As dimensões escalares do Desenvolvimento Regional: o caso da evolução do turismo em Gramado-RS. Colóquio, Taquara, 2014, v. 11, p. 150-161. 